\title{
Purification of Staphylococcal Enterotoxin Type D and Obtaining Its Antiserum
}

\author{
Bidjeh Kebkiba $^{1,}$, , Ban-Bo Bebanto Antipas ${ }^{2}$, Podkapaev Vladimir Michaelovich ${ }^{3}$ \\ ${ }^{1}$ Livestock Research Institute for Development (IRED), Ndjamena, Chad \\ ${ }^{2}$ Faculty of Exact and Applied Sciences, University of Ndjamena, Ndjamena, Chad \\ ${ }^{3}$ Veterinary Academy in Moscow, KI Skriyabin, Moscow, Russia \\ Email address: \\ bidjeh.kebkiba@gmail.com (B. Kebkiba),bidjehkebkiba@yahoo.fr (B. Kebkiba)
}

\section{To cite this article:}

Bidjeh Kebkiba, Ban-Bo Bebanto Antipas, Podkapaev Vladimir Michaelovich. Purification of Staphylococcal Enterotoxin Type D and Obtaining Its Antiserum. Animal and Veterinary Sciences. Vol. 3, No. 6, 2015, pp. 166-170. doi: 10.11648/j.avs.20150306.14

\begin{abstract}
Uncontrolled use of antibiotics in the treatment of calves suffering from gastroenteritis and dairy cows suffering from mastitis, created in pathogenic staphylococci enterotoxin producers some resistance to these drugs. These pathogens enterotoxin producers are often excreted with milk from cows with mastitis. That is why the specific and topical issue remains the isolation and identification of strains producing staphylococcal enterotoxin from cow milk and faeces of calves suffering from enteritis. Given all this, we have set a goal to get staphylococcal enterotoxin type D for use as mastitis diagnostic kit and enteritis and antigen for obtaining the antiserum. To obtain the staphylococcal enterotoxin type D we used strain S. aureus No. 494 (ATSS23235) courtesy offered by Dr. FC Fluer from Institute of Experimental Medicine, NF Gamaley, Medical Academy (USSR). Verification of the specificity of the enterotoxin) was performed using 5 strains of S.aureus producing different enterotoxins (enterotoxin - A; enterotoxin-B; enterotoxin $\mathrm{C}_{-1} ; \mathrm{C}_{-2}$ and enterotoxin - E) as well as non-enterotoxigenic staphylococcal strain ( $S$. aureus Wood 46). In addition to the staphylococcal strains, five strains of Escherichia coli, producing thermostable and thermolabile enterotoxins were also used in the experiment. The method of purification of enterotoxin-D by precipitation twice chromatography on km - cellulose and gel filtration on Sephadex G-75 allows to obtain pure enterotoxin-D having the biological properties, immunological and antigenic characteristics. Immunization of rabbits with purified enterotoxin-D associated with incomplete Freund's adjuvant provides antiserum very active and specific.
\end{abstract}

Keywords: Staphylococcus aureus, Milk, faeces, Enterotoxin, Antiserum, Enteritis

\section{Introduction}

Some researchers VA Alikaev et al.; PB Barto et al.; MA Volovenko and BV Venskiyavitchen $[1 ; 32 ; 40 ; 41]$ reported that a high percentage of recorded gastro enteritis in calves is mainly due to the ingested milk from cows suffering from mastitis. In the aetiology of gastro-enteritis of calves, it is important to also consider non-compliance with hygienic rearing conditions of these young animals. Many authors believe that young animals become contaminated with microorganisms such as enterotoxigenic Staphylococcus aureus and Escherichia coli, through the ingestion of colostrum or milk from cows suffering from mastitis [3]. The role of enterotoxigenic staphylococci in the aetiology of gastro-enteritis in calves remains to be elucidated. There are in the literature data on the purification methods of staphylococcal enterotoxin type D and its identification in the milk or colostrum and other food. However, these authors have used more complex methods for purification and for obtaining the antiserum. Also, the methods used by these authors are difficult to apply in laboratories in developing countries [4]. Milk from cows with mastitis represents a great danger to human health, particularly for infants and the elderly $[18 ; 22]$.

Until the $20^{\text {th }}$ century, most of authors $[5 ; 12 ; 19 ; 20 ; 33 ; 34]$, used kittens for biological test to identify the staphylococcal enterotoxin, but rarely mice and pups, as they are insensitive. By cons, in the United States of America, the monkey genus rhesus Macacca was used for this test. Also note that the identification of staphylococcal enterotoxin by the biological test is laborious and time consuming and the results are still not satisfactory. Also, for the biological testing a significant number of animals require; In addition, this method only allows detecting the presence of enterotoxin, but does not give rise to know the serotype of the offending enterotoxin 
inducing Intoxication. The aim of this work is to develop a simple method of purification of staphylococcal enterotoxin type D for use as an antigen in immunization of rabbits in order to obtain the antiserum for diagnosis of enteritis due to staphylococci enterotoxin-D producing.

\section{Materials and Methods}

To obtain the staphylococcal enterotoxin type D we used strain S. aureus No. 494 (ATSS23235) courtesy offered by Dr. FC Fluer from Institute of Experimental Medicine, NF Gamaley, Medical Academy (USSR). To verify the specificity of the enterotoxin we used 5 strains of $S$. aureus enterotoxins producing such as: FRI 722- enterotoxin- A; FRI-243-enterotoxin- B; FRI-137-enterotoxin $\mathrm{C}_{-1}$; FRI-493enterotoxin $\mathrm{C}_{-2}$ and FRI-326 enterotoxin-E), and non-enterotoxigenic staphylococcal strain (S. aureus Wood 46). In addition to the staphylococcal strains, five strains of Escherichia coli (E. P16, E. 1012, and E.015 - H10407, thermostable enterotoxin-producing; E.coli-P99, producing heat-labile enterotoxin, have also been used in the experiment. The morphological, dyeing, biological and enzymatic properties of 7 strains of S.aureus indicated above as well as strains isolated from faeces of calves with diarrhea and cow milk-producing staphylococcal enterotoxin-D were studied by the method of KI Mateveev; BA Nourmatov et al. and AK Akatov et al. [24; 23; 25]. In the experiment, 10 rabbits, genus chinchilla weighing 2.5-3 grams each; 180 kittens 1-3 months of age and weighing 350-700 g each, were used. Material containing the enterotoxin is obtained according to the method of. of CE Donnelly et al. [31] by cultivating the S. aureus strain No. 494 in the plastic bag under continuous stirring at a rate of 280-300 rounds / min for 24-48 hours and the ventilation method, which involves passing air through medium through the two filters using a micro compressor mark VK-1 $(220 \mathrm{~V}, 50 \mathrm{~Hz}, 10 \mathrm{watt})$. To obtain the maximum concentration of staphylococcal enterotoxin type D, 5 different culture media were tested. These are: Medium $n^{\circ} 1$. [26], modified by VI Bougrova et al. [6]; Medium n ${ }^{\circ}$. [29]; Medium $n^{\circ} 3$. [30], Medium $n^{\circ} 4$ [42] and Medium n ${ }^{\circ}$ [46]. All of these media are prepared on the basis of casein hydrolyzat and supplemented amino acids and vitamins in different concentrations. The activity of the enterotoxin is set to kittens by the method of [33]. Purification of enterotoxin is performed according to the method of K. Bidjeh, [4], which comprises of passing (2 times) the solution containing enterotoxin on km- cellulose and on sephadex G-75 gel. The homogeneity of the enterotoxin has been defined by the disc electrophoresis method as in acid system [39] that in the basic system [28] in a gel (7.5\%) of polyacrylamyl using the reagents and the electrophoresis apparatus (Reanal, Hungary).Some physicochemical properties of enterotoxin-D were studied as follows: heating at 80,90 and $100^{\circ} \mathrm{C}$. for 15 , 30 and 60 minutes, and by studying the action of certain enzymes such as trypsin, pepsin, renin and hemotrypsin (all at a concentration of $0.3 \%$ ).

For antisera, 8 rabbits were immunized according to the method of EP Casman et al. [46]. Purified enterotoxin mixed with Freund's incomplete adjuvant in equal parts, injected into rabbits intramuscularly at increasing dosis ( $\mathrm{mg}$ protein $/ \mathrm{ml})$ $0.10 ; 0.10 ; 0.15 ; 0.2 ; 0.3 ; 0.4 ; 0.6 ; 0.8 ; 0.9 ; 1.2 ; 1.6 ; 1.6 ; 1,6$ at 6- 7 days interval. In the control group, two non-immunized rabbits were used. The action and specificity of the antiserum have been defined by the agar immunodiffusion reaction (AGID) in petri dishes by the method of Ouchterlony O. [38] and in tubes. For the reaction of immunoelectrophoresis (IEP) is the method of P. Graber et al. [48] was used. 10 days after the $13^{\text {th }}$ injection, rabbits were bled. After clotting, the clot is removed and the serum is obtained by centrifuging the contents of the tubes at $3000 \mathrm{rpm} / \mathrm{min}$ for 30 minutes and stored at $-20^{\circ} \mathrm{C}$. The resulting serum of each animal is considered as a serial. A total of 4 series of serum was obtained. The sera are then distributed in tubes and kept at $-20^{\circ} \mathrm{C}$ for further use.

\section{Results}

Purification of enterotoxin - D and its physicochemical properties

Purification of enterotoxin-D is carried out as follows: after passing on km-cellulose (twice), washing is done on the gel Sephadex G-75 with distilled water until obtaining the $\mathrm{pH}$ neutral (7.0). After lyophilization, entering the second step on $\mathrm{km}$-cellulose. After that, it was noted that only peak 3 had biological activity and the bioassay was positive on kittens. By repeating chromatography on $\mathrm{km}$-cellulose, it has been found that a single peak eluting had a positive biological effect on kittens. The results of the disc-electrophoresis of eluent on polyacrylamil gel obtained after the $3^{\text {rd }}$ purification step, showed that enterotoxin was not homogeneous because on the gel appeared two precipitation lines, indicating the presence of the second element in the solution (eluent), which is nothing other than $\alpha$-hemolysin, which has been shown by the action hemolytic eluent on erythrocytes of rabbits. After $4^{\text {th }}$ purification step on Sephadex, only the second peak of eluting possessed a biological action on kittens. The homogeneity of the enterotoxin is demonstrated by the appearance of a single precipitation line on the gel and the absence of hemolytic activity on erythrocytes of rabbits. It has been shown that both the purified enterotoxin and unpurified were resistant to the action of proteolytic effect of enzymes $(0.3 \%)$ such as pepsin, trypsin, hemotrypsin and renin. Enterotoxin both purified and non-purified is destroyed at the temperature ranged between 85 and $100^{\circ} \mathrm{C}$ for 25 minutes as they lose their antigenic properties.

Obtaining antiserum enterotoxin- $D$ and its specific action by immunodiffusion tests on agar (AGID), precipitation in tubes (IPT) and the immunoelectrophoresis test (IEP)

The activity of each serum is checked by the AGID and IPT tests. Both by the AGID as other immunochemical tests, the antiserum revealed the homogeneity of enterotoxin-D to the minimum concentration of protein of $10,62 \mathrm{mg} / \mathrm{ml}$, which is demonstrated by the appearance of one line of precipitation between the wells containing the enterotoxin-D and those 
containing antiserum at different dilutions: from $1 / 2$ to $1 / 32$.

The specificity of the antiserum obtained was checked by various tests: Agar gel immuno diffusion (AGID), immuno-precipitation in tubes (IPT) and immunoelectrophoresis (IEP) vis-à-vis the heterogeneous enterotoxins (Table 1.). From this table, we can see that antiserum anti-enterotoxin- D has been very specific because it does not react with the filtrates of enterotoxigenic staphylococci producing enterotoxin types: $\mathrm{A}, \mathrm{B}, \mathrm{C}_{1}, \mathrm{C}_{2}$ and $\mathrm{E}$ and $\mathrm{S}$. aureus strain producing $\alpha$ and $\beta$ - hemolysin. As it can be seen from the said table 1 , antiserum anti-enterotoxin-D does not react with any of these above mentioned antigens. Similar results were found with the supernatant of E. Coli $\mathrm{N}^{\circ} 1012$, E; coli $\mathrm{P} 16$ and E. coli H10407 producers of thermostable enterotoxin (TS); E. Coli $\mathrm{N}^{\circ} 015-339$, heat-labile enterotoxin Producer (TL). We recorded the same results with A-enterotoxin of Cl. Perfringens.

Table 1. Specificity of the antiserum anti-enterotoxin-D in AGID, PT and IEP tests.

\begin{tabular}{lllll}
\hline Antigens & $\begin{array}{l}\text { Protein concentration } \\
\text { mg/ml }\end{array}$ & \multicolumn{2}{l}{ Results } \\
& & IDG & IPT & IEP \\
\hline S. enterotoxin-A & 6000 & - & - & - \\
S. enterotoxin-B & 6000 & - & - & - \\
S. enterotoxin C 1 & 5000 & - & - & - \\
Enterotoxin C $_{2}$ S. & 5000 & - & - & - \\
S. -E enterotoxin & 4000 & - & - & - \\
$A$ and $\beta$-S. hemolysins & 6000 & - & - & - \\
TS E.coli 1012 & 3900 & - & - & - \\
TS P 16 E. coli & 3900 & - & - & - \\
TL E. Coli P99 & 3900 & - & - & - \\
TS, TL E. coli H10407 & 3900 & - & - & - \\
E.coli 015-339 & 3900 & - & - & - \\
CL. perfringens-A & 170 & - & - & - \\
S. enterotoxin-D & 4000 & + & + & + \\
\hline
\end{tabular}

NB.: For staphylococcal enterotoxin types A, B, C $1, C_{2}$, D and E, the supernatant that was used in the experiment. As for the enterotoxin-A of $\mathrm{Cl}$. Perfringens is the purified product, which was used.

Demonstration of enterotoxin $-D$ in the faeces of calves suffering from enteritis and in the milk or colostrum of cows suffering from mastitis.

In the study no positive reaction was found with faeces from healthy calves. By cons, among the 30 faecal samples from calves, $8(26,66 \%)$ reacted positively with antiserum anti-enterotoxin -D by AGID test; 2 (6.66\%) yielded questionable results by the same test. The presence of enterotoxin - D has been demonstrated in $6(75 \%)$ faecal samples from calves aged from 5 to 8 days. In 2 (25\%) of cases, the results were also positive with faeces from calves aged 1 to 7 days. 2 (25\%) calves, whose samples were positive with antiserum anti-enterotoxin-D, were aged between 4 and 7 days respectively. The age groups corresponding to the period when calves are often suffering from enteritis were divided as follows: 1, 3, 5 and 6 days. The study of infected pasteurilised milk with staphylococcal colonies producing enterotoxin- D at a concentration of $10^{3}$ and $10^{5} / \mathrm{ml}$ did not reveal the presence of enterotoxin -D in any case regardless of the incubation time at $37^{\circ} \mathrm{C}$ for $3,6,18$ and 24 hours. By cons, in the samples of pasteurellised milk infected with $S$. aureus at a concentration of $10^{6}-10^{9}$ and incubated at $37^{\circ} \mathrm{C}$ for $18-24 \mathrm{~h}$, there was secretion of enterotoxin-D, Which allows deducing that the speed of secretion of enterotoxin-D depends on the quantity of microorganisms in the medium and the incubation time. The study of 95 samples of milk with 5\% dimastin solution showed that the reaction was positive in only $36(37.8 \%)$ cases. In contrast, with the immunochemical test (AGID), no sample was positive vis-a-vis the antiserum anti-enterotoxin-D. However, of 17 samples of colostrum tested, only 2 (11.76\%) reacted positively with antiserum anti-enterotoxin-D by AGID test. This is explained by the fact that among the cow milk, the concentration of enterotoxin is so low that we cannot detect with AGID test, while in cows that have given birth, the possibility of revealing the presence of enterotoxin-D is the first milking.

\section{Discussion}

In general, increased animal production requires industrialization in this area and the creation of large livestock complexes. However, infectious diseases such as enteritis due to staphylococci significantly reduce growth in the number of cattle in dairy farms. The information collected in different scientific journals shows the possible role of enterotoxigenic staphylococci in enteritis of calves and mastitis in dairy cows excreting enterotoxigenic staphylococci with milk and constituting potential sources of diseases such as food poisoning, gastroenteritis, etc. $[1 ; 2 ; 3 ; 4 ; 9 ; 10 ; 11 ; 13 ; 14 ; 16$; $17 ; 27 ; 35 ; 39 ; 40 ; 41 ; 45 ; 50]$. However, the role of staphylococci producing enterotoxin- D in the aetiology of these diseases is poorly understood and the simplified method of identifying the enterotoxin in faeces of calves suffering from enteritis has not been in focus. It is the same for the milk of cow carriers of pathogenic staphylococci. EH Kato et al.[35]; MS Berdoll [43]; KN Shinagawa Kunita [49]; EP Casman et al.[46] described the methods of purification and identification of the staphylococcal enterotoxin type D in milk and colostrum from cows, but the authors used for these purposes complex methods difficult to implement in the conditions of laboratories in developing countries. These shortcomings noted have led us to use the four-step purification of staphylococcal enterotoxin-D.

Today, the most effective diagnosis of enterotoxicoses caused by staphylococci can be done with the immunochemical test that gives accurate and satisfactory results. For use, it is necessary to have the purified enterotoxin and the antiserum $[4 ; 21 ; 47 ; 15 ; 44]$. However, in the veterinary field, the development of such reagents requires the development of special technology for extraction, purification of enterotoxin and obtaining the homologous antiserum.

By immunizing rabbits with enterotoxin-D, it was noted that it is only at the $9^{\text {th }}$ injection that was able to detect antibodies directed against enterotoxin-D ( $1 / 2$ of dilution). Then, antibody titers increased progressively up to $1 / 8$ according to increase in the dose of the antigen. Also note that in the immunization process, 4 rabbits $(50 \%)$ died, 
demonstrating the toxicity of enterotoxin-D. The use of this immunization scheme of rabbits demonstrates once again that enterotoxin-D, like other staphylococcal enterotoxins have low antigenic property.

Many problems associated with the effect of colostrum from cows suffering from mastitis and carrier enterotoxigenic staphylococci. These problems have not previously found solutions, while the spread of enterotoxicoses of calves are recorded every day and this number increases rapidly [40;3]. The antiserum obtained is one of the possible solutions to these problems. As it will detect the presence of enterotoxin-D in the milk / colostrum from cows suffering from mastitis and in the faeces of calves suffering from gastroenteritis.

\section{Conclusion}

The method of purification of enterotoxin-D by precipitation twice chromatography on $\mathrm{km}$-cellulose and gel filtration on Sephadex G-75 allows to obtain pure enterotoxin-D having the biological properties, immunological and antigenic characteristics of staphylococcal enterotoxin.

Immunization of rabbits with purified enterotoxin-D associated with incomplete Freund's adjuvant provides antiserum very active and specific. Obtaining purified enterotoxin and the antiserum thus offering use the immunochemical method for the detection of enterotoxin-D in the supernatant of faeces of sick calves and dairy cows carrier pathogenic staphylococci.

\section{References}

[1] Alikaev VA, VV Matuchin. Fight against calves gastroenteritis. Veterinariya, 1982, 4, 51-55.

[2] Alikaev VA. Prophylaxis of cow diseases in industrial livestock complexes. Moscow kolos, 1976, 192p.

[3] Abzaloba AG. Mastitis and gastroenteritis. Uralski Nivi, 1978, 3, 52-53.

[4] Bidjeh K. Development of identification method of staphylococcal enterotoxin type D in milk /colostrum of cows and in the faecal samples of calves suffering from enteritis. phD thesis, Veterinary Academy of Moscow KI Skriyabin, Moscow, 1984, 176p.

[5] Baïliozov D. B., Panaïtova M., Visiolinov V.O. About the identification method of staphylococcal enterotoxin. JMEI, 1962, 8, 101-109.

[6] Bougrova V.I., Nikolaeva I.S. obtaining the enterotoxin- A for the diagnosis of staphylococcal intoxication. Vapros pitani, 1974.6, 47-52.

[7] Berdoll MS. The nature of staphylococcal enterotoxins. Clinical toxicol. 1972, 5, 4, 441.

[8] Berdoll MS, Huang IY, Schantz EJ. Chemistry of staphylococcal entertoxins. J. Agric. Food Chem., 1974, 22, 9-13.

[9] Winduga Bozena. Occurrence of enterotoxigenic staphylococci especially producors of entertoxin- D and E among Strains isolated from food. Acta food. Pol., 1978, 4, 2, 129-132.

[10] Kartachova V.M. Fast detection method of staphylococcal toxin in milk and dairy products. Veterinariya, 1970, 11, 105-107.

[11] Kartachova V.M. Methods for identifying staphylococci and their toxins in milk and milk products. In: Identification of pathogenic bacteries in milk and milk products, Moscow, Kolos, 1973, 108-148.

[12] Kuchko I.V., Xatmever M.L., Akatov A.K. About the possibility of the method of use of part of the intestine ligature of experimental animals for identification of enterotoxins. In: The problem of staphylococcal infections. Tch. I. Saratov, 1979, 13-15.

[13] Minor T.E., Mart E.X. Staphylocci in food products, Moscow, 1980. 231p.

[14] Niskanen A., Korainen L., Roine K. Staphylococcal enterotoxin and Thermonuclease production during the induced bovine mastitis and the clinical reaction of enterotoxin in Udders. Infection and Immunity, 1978, 19, 2, 493-498.

[15] Sabri Darvich Morgan Selim. Immunochemical Method identification of the staphylococci producing enterotoxin-A isolated from cows with mastitis. phD thesis, 1979 178, 178p.

[16] Santos E.C., Moreira H.A. Influence of mastitis induced by staphylococcal enterotoxin protein on the composition of bovine milk. Arg. E sc. Vet., 1976, 28, 3, 227-232.

[17] Santos E.C., Moreira H.A. Influence of staphylococcal mastitis induced by enterotoxin on production of bovine milk. Arg. E sc. Vet., 1977, 29, 1, 5-10.

[18] Slavchev G. Economic importance of sub/clinical mastitis in cows. Vet. Sb., 1982, 80, 8, 34-36.

[19] Stolmakova A.I. Food poisoning original staphylococci. University of Lvov, Lvov, 1959. 22p.

[20] Stolmakova A.I. Experimental poisoning of animals by the staphylococcal enterotoxin, 1954, 13, 5, 28-33.

[21] Fluer F.S. Some physicochemical, structural and functional properties of staphylococcal entertoxins. JMEI, 19, 80, 12, 9-17.

[22] Mutovin V.I. Fight against mastitis of cows, Moscow, 1974, $254 p$.

[23] Nourmatov B.A., Dvites NE. Bacteriological diagnostic of staphylococcal infections (methodological Recommendations) Tashkent, 1978, 22p.

[24] Mateveev K.I. Annals of microbiological diagnosis of infectious diseases, $2^{\text {nd }}$ ed, Moscow, 1973, 624p.

[25] Akatov A.K., Zueva V.S. Staphylococci, Medicine, Moscow, 1983, 256p.

[26] Casman E.P. Serological studies of staphylococcal Enterotoxins. Public health, report, 1958, 73, 599-609.

[27] Casman E.P, Berdoll M.S., Robinson J. Designation of staphylococcal enterotoxins. J. Bacteriol., 1963, 85, 715-716.

[28] Davis B.J. Disc electrophoresis. II. Method and Application to human proteins. Ann. NY Acad. Science 1964, 121, 404-427. 
[29] Jarvis A.W. and Lowrence R.C. Production of high titers of Enterotoxins for the routine testing of staphylococci. Applied Microbiology, 1970, 19, 4, 698-699.

[30] Noleto A.L. and Berdoll M.S. Staphylococcal enterotoxin Production in the non-enterotoxigenic staphylococci. Applied and Environmental Microbiology, 1980, 39, 6, 1167-1171.

[31] Donnelly C.B., leslie J.E., Black LA. Serological identification of enterotoxigenic staphylococci in cheese. Applied Microbiology, 1967, 15, 1382-1387.

[32] Barto P.B., Bush L.J., Adams G.D. Effect of sour colostrum on survival of Staphylococcus aureus. Animal Science Research report, 1979.104, 265-326.

[33] Dolman E.C., Wilson R G. The kitten test for staphylococcal enterotoxin. Canadian Journal of Public Health, 1940, 31, 68-71.

[34] Hammon Mcd. W. Staphylococcal enterotoxin: An Improved cat test. Chemical and immunological studies. Am. J. Public Health, 1941, 31, 1191-1198.

[35] Kato Tsuneo E. and Kume. Enterotoxigenicity of staphylococci isolated from bovine mastitis California test- positive milking. Japan. J. Vet. Res. 1980, 28, 3, 75-85.

[36] Olson J.C., Casman E.P., Berdoll M.S. Enterotoxigenicity cultures of staphylococcus aureus isolated from bovine mastitis of acute cases. Journal of applied microbiology, 1970, 20, 4, 605- 607.

[37] Ostachevski A.G., Obrassov V.P., Kotenko I.I. Using the precipitation reaction for the identification of enterotoxigenic staphylococci. Trudi kharkov, zoovet., Institute., 1970 (1971), 5, 29, 22-26.

[38] Ouchterlony. Antigen antibodies reactions in gels. Acta Patholol. Microbiol. Scand., 1949, 25, 507-515.

[39] Reisfeld R.A., Lewis U.J., Williams D.E. Disc electrophoresis of proteins in basic polyacrylamid gels. Nature 1962, 195, 281-283.
[40] Volovenko M.A. Effect of colostrum and milk products coming from cows with mastitis on natural resistance and morbidity of calves. PhD Thesis, Kharkov, 1975173 P.

[41] Venskiyavischen V.B. Effect of udder on the morbidity of calves. Bulletin of the Scientific and Technological Information, 1967.1, 46-47.

[42] Favourite G.O., Hammon W.M. Production of staphylococcal toxin, enterotoxin and alpha hemolysin in a simplified medium. Journal of bacteriology, 194,141, 305-316.

[43] Berdoll M.S. Staphylococcal poisoning. In: H. Riemann and Bryan F.L. (ed) Food borne infections and intoxications $2^{\text {nd }}$ ed. Academic Press, New York, 1979, 443-494.

[44] Berdoll MS, H. Sugiyama, Dack GM. Staphylococcal enterotoxin I. Purification. Ach. Bioch. Biophys., 1959, 85, 85-89.

[45] Bozena Z.S. Enterotoxigenicity of staphylococci isolated from cow milk with mastitis. Medecin veterinariya 1980, 36, 6, 368-370.

[46] Casman E.P., Bennet R.W., Dorsey A.E. Issa J.A. Identification of staphylococcal enterotoxin D, fourth serotype. Bacteriology, 1967, 94, 6, 1875-1882.

[47] Chang H.C. and Berdoll M.S. Purification of Reduced and Some properties of staphylococcal enterotoxin-D. Biochemistry 1979, 18, 1937-1942.

[48] Graber P. Immunoelectrophoretic analysis. Methods Biochem. $19597,1-38$

[49] Shinagawa K., N. Kunita Simplified methods for purification of staphylococcal Enterotoxins A and C and preparation of anti - enterotoxin. Jap. Bacterial J. 1975, 30, 6, 683-692.

[50] Tingting zhang, Anning Huang, Junnian Li, Liu Xinqin, Liuli, $\mathrm{Lu}$ Yao, Ying Huang and Wang WinPing. Characterization of antimicrobial resistance and enterotoxin in meticillin - resistant Staphylococcus aureus isolated from milk and food poisoning cases. Journal of animal and veterinary advances, 201413 (7) 423-429. 